07.2;08.2;13.1;13.4

\title{
Изучение эффективности теплоотвода композитных подложек „кремний на алмазе“ для устройств на основе нитрида галлия
}

\author{
() И.С. Езубченко, М.Я. Черных, И.А. Черных, А.А. Андреев, И.О. Майборода, Е.М. Колобкова, \\ Ю.В. Храповицкая, Ю.В. Грищенко, П.А. Перминов, М.Л. Занавескин
}

Национальный исследовательский центр „Курчатовский институт“, Москва, Россия

E-mail: ezivan9@gmail.com

Поступило в Редакцию 21 декабря 2021 г.

В окончательной редакции 12 января 2022 г.

Принято к публикации 19 января 2022 г.

\begin{abstract}
Выполнены термометрические измерения встречно-штыревых структур на основе нитрида галлия, созданных на композитных подложках „кремний на алмазе“. Проведено сравнение эффективности теплоотвода с аналогичной характеристикой в случае использования стандартной технологии „нитрид галлия на карбиде кремния“. Показано, что использование нового типа композитных подложек „кремний на алмазе“ позволяет понизить температуру поверхности более чем на $50^{\circ} \mathrm{C}$ по сравнению со случаем применения подложек карбида кремния при рассеиваемой мощности выше $7 \mathrm{~W}$. Предложенный подход является перспективным для увеличения выходной мощности устройств на основе нитрида галлия, а также для увеличения их надежности.
\end{abstract}

Ключевые слова: нитрид галлия, теплоотвод, алмаз, рассеиваемая мощность.

DOI: 10.21883/PJTF.2022.07.52287.19111

Нитрид-галлиевые $(\mathrm{GaN})$ гетероструктуры успешно применяются в устройствах связи, радарах и вторичных преобразователях энергии [1]. Высокие значения удельной плотности тока и пробивного напряжения позволяют получать $\mathrm{GaN}$-элементы с удельной выходной мощностью более $5 \mathrm{~W} / \mathrm{mm}$ [2]. Однако используемые для эпитаксии гетероструктур подложки из кремния и карбида кремния ( $\mathrm{SiC})$ обладают сравнительно низкой теплопроводностью, что приводит к существенному нагреву активной области транзисторов. Саморазогрев структуры ограничивает потенциал выходной мощности и уменьшает время наработки приборов до отказа. Алмаз обладает рекордным значением теплопроводности среди объемных материалов. Коэффициент теплопроводности пленок поликристаллического алмаза, выращенных методом химического осаждения из газовой фазы в СВЧ-разряде, достигает значений 800-1800 W/(m/K) [3]. Поэтому алмаз является перспективным материалом для создания эффективного теплоотвода из активной области GaN-транзисторов.

На данный момент продемонстрировано несколько способов интеграции гетероструктур нитрида галлия и алмазного теплоотвода (GaN-on-diamond) [4-6]. Однако до сих пор существенных результатов по снижению температуры активной области транзисторов достичь не удалось. Этот факт сдерживает внедрение технологий GaN-on-diamond в СВЧ-устройствах высокой мощности.

В работах [7,8] нами был продемонстрирован оригинальный масштабируемый подход к интеграции GaNгетероструктур с алмазным теплоотводом, были созданы $\mathrm{GaN}$-гетероструктуры приборного качества на подложках размером $15 \times 15 \mathrm{~mm}$, на их основе сформированы транзисторы, изучены их статические характеристики.
В настоящей работе проведены исследования температуры поверхности встречно-штыревых структур с целью изучения эффективности теплоотвода композитных подложек GaN-on-diamond, а также выполнено сравнение результатов со стандартной технологией GaN-on-SiC.

Для исследования в качестве опорных образцов использовались коммерчески доступные транзисторы $\mathrm{GaN}-\mathrm{on}-\mathrm{SiC}$ с расстоянием исток-сток $4 \mu \mathrm{m}$, периодом $25 \mu \mathrm{m}$, длиной затвора $0.2 \mu \mathrm{m}$ и общей периферией затвора 1.25 mm (TGF2023-2-01, Qorvo, США). Затвор был предварительно закорочен на исток транзистора, чтобы исключить влияние эффектов плавающего затвора. Для корректного сравнения были изготовлены топологические аналоги встречно-штыревых структур GaN-on-diamond.

Технология создания композитных подложек GaN-ondiamond представлена в работе [7]. Монтаж транзисторных кристаллов осуществлялся в металлокерамический корпус мощного транзистора. С целью обеспечения низкого теплового сопротивления кристалл-корпус был выбран метод напайки при помощи эвтектического сплава Au80/Sn20. Использовался сплав в виде кусочка фольги толщиной $25 \mu \mathrm{m}$. Основание корпуса транзистора пластина из псевдосплава $\mathrm{Cu}-\mathrm{W}$ толщиной $2.5 \mathrm{~mm}$, покрытая слоем гальванического золота толщиной около $5 \mu \mathrm{m}$. Корпус прибора с кристаллами был смонтирован на массивный медный теплоотвод, для улучшения термического контакта использовалась термопаста. Разварка внутренних выводов СВЧ-транзисторов проводилась на установке F\&K Delvotec 5630 золотой проволокой диаметром $25.4 \mu \mathrm{m}$.

Измерение зависимостей температуры поверхности от величины рассеиваемой мощности выполнялось в 


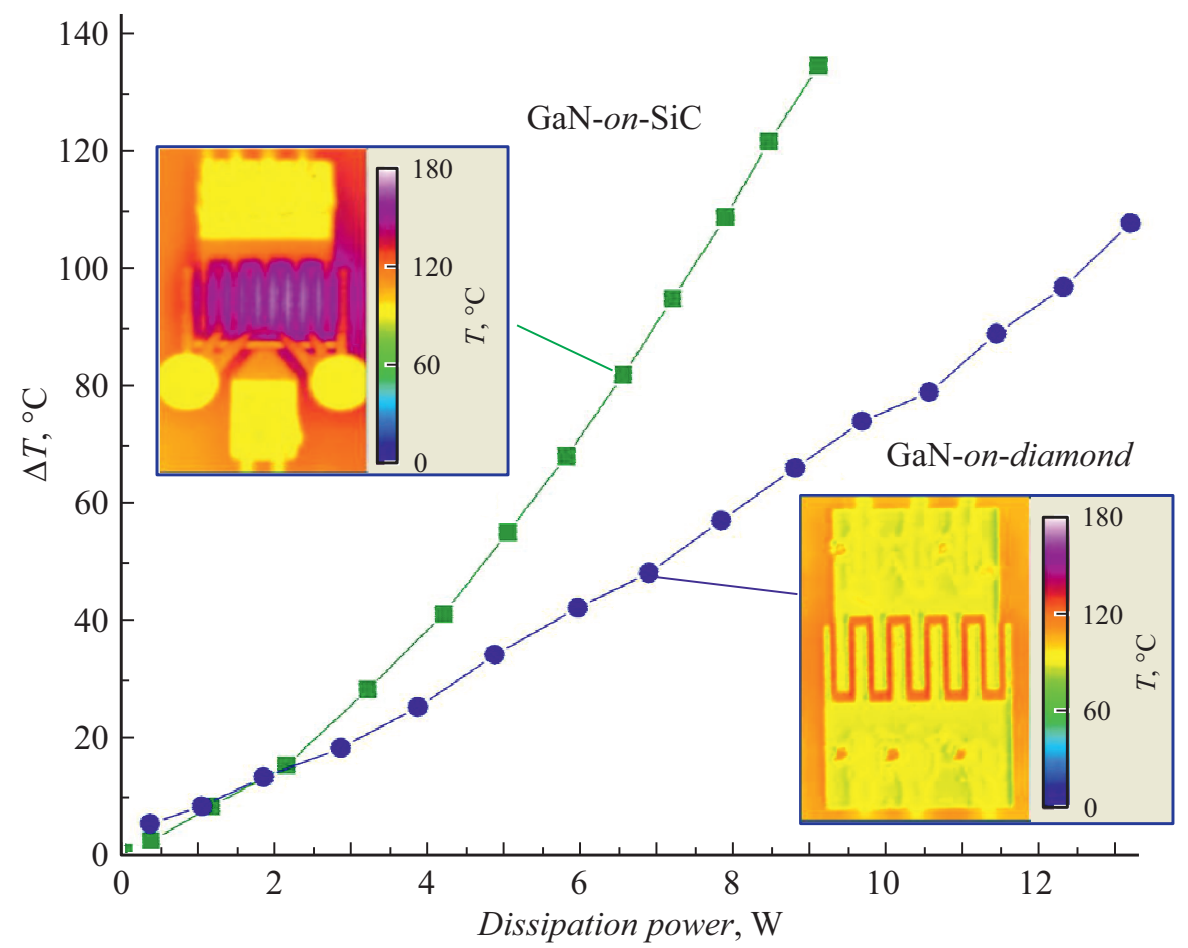

Рис. 1. Зависимость повышения максимальной температуры активной области транзистора относительно температуры основания $\Delta T$ от рассеиваемой мощности для транзисторных структур GaN-on-SiC и GaN-on-diamond. На вставках — карты распределения температуры на транзисторных структурах $\mathrm{GaN}-\mathrm{on}-\mathrm{SiC}$ и GaN-on-diamond при рассеиваемой мощности $6.6 \mathrm{~W}$.

режиме постоянного тока на установке термомикроскопического анализа QFI's InfraScope. Изменения температуры регистрировались камерой MWIR с охлаждением жидким азотом, работающей на длине волны $1-5 \mu \mathrm{m}$. Карта интенсивности $1000 \times 1000$ пикселей и поле зрения $750 \times 750 \mu \mathrm{m}$ дают разрешение примерно $0.75 \mu \mathrm{m}$ на пиксель. Установка оснащена термостабилизированным столом с диапазоном поддерживаемых температур $10-140^{\circ} \mathrm{C}$. Чувствительность прибора составляет $0.1^{\circ} \mathrm{C}$.

Измерения проводились при температуре основания $85^{\circ} \mathrm{C}$, являющейся опорной точкой при работе устройств в условиях возможности использования только воздушного внешнего охлаждения.

Измерение вольт-амперных характеристик (BAX) проводилось на зондовой станции Cascade PM5 c помощью двухканального источника-измерителя Keithley 2636B.

На рис. 1 представлена зависимость повышения максимальной температуры активной области транзистора относительно температуры основания $\Delta T$ от рассеиваемой мощности.

Производители дискретных транзисторов GaN-on-SiC не рекомендуют использовать режимы работы, в которых температура канала превышает $200^{\circ} \mathrm{C}$, так как это приводит к существенному уменьшению времени наработки до отказа. В частности, для опорного транзистора температура поверхности, заявленная производителем, не должна превышать $184^{\circ} \mathrm{C}$ при максимальной реко- мендуемой рассеиваемой мощности $6.25 \mathrm{~W}$ в режиме постоянного тока. Это соответствует значению $\Delta T=99^{\circ} \mathrm{C}$ и совпадает с результатом, приведенным на рис. 1. При рассеиваемой мощности $8.5 \mathrm{~W}$ разогрев $\Delta T$ для структуры на $\mathrm{SiC}$ уже превышает $120^{\circ} \mathrm{C}$, в то время как для структуры на алмазе $\Delta T$ составляет менее $70^{\circ} \mathrm{C}$. Такая разница температур соответствует различию времени наработки до отказа кристаллов на два порядка [9]. В то же время $\Delta T=115^{\circ} \mathrm{C}$ (что соответствует температуре канала $200^{\circ} \mathrm{C}$ ) для структур на алмазе достигается при рассеиваемых мощностях более $13 \mathrm{~W}$. Также на рис. 1 (см. вставки) приведены карты распределения температуры, полученные при рассеиваемой мощности, равной $6.6 \mathrm{~W}$ (это значение соответствует типичной для современных устройств удельной мощности $\sim 5 \mathrm{~W} / \mathrm{mm}$ ). Максимальная температура в рабочей области канала транзистора на $\mathrm{SiC}$ составила $172^{\circ} \mathrm{C}$, что соответствует времени наработки до отказа менее $10^{9} \mathrm{~h}$. Для структуры на алмазе максимальная температура в рабочей области канала составила $133^{\circ} \mathrm{C}$. С учетом данных по исследованиям в области наработки устройств до отказа транзисторы на базе GaN-on-diamond потенциально смогут обеспечить более $10^{11} \mathrm{~h}$ стабильной работы в данном режиме [9].

Таким образом, предложенная технология формирования алмазного теплоотвода позволяет повысить время наработки до отказа или рассеиваемые мощности при сохранении температур каналов транзисторов. Приме- 


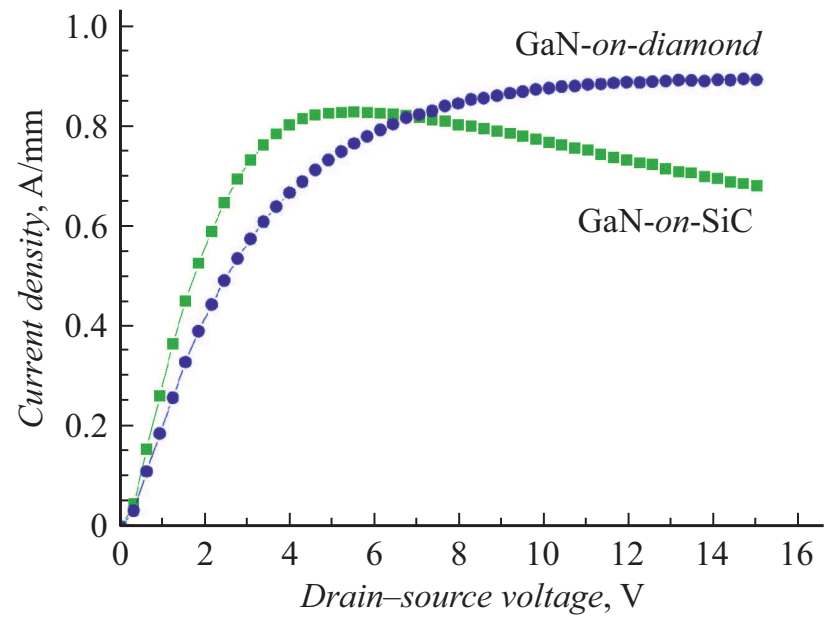

Рис. 2. Вольт-амперные характеристики транзисторов $\mathrm{GaN}$-on-SiC и встречно-штыревых структур GaN-on-diamond.

нение данной технологии позволит уменьшить площадь активной области транзистора при сохранении общей ширины затвора.

На рис. 2 представлены измеренные ВАХ структур. Максимальная плотность тока стока для транзисторов GaN-on-SiC и встречно-штыревых структур GaN-on-diamond составила 0.82 и $0.88 \mathrm{~A} / \mathrm{mm}$ соответственно. Видно, что для транзисторов GaN-on-SiC при напряжениях выше $6 \mathrm{~V}$ существует область падения тока стока из-за эффекта саморазогрева, в то время как для встречно-штыревых структур GaN-on-diamond саморазогрев отсутствует во всем диапазоне измерений. Таким образом, структуры $\mathrm{GaN}$-on-diamond позволяют повысить рассеиваемую мощность на $37 \%$ при напряжении питания $15 \mathrm{~V}$.

В заключение отметим, что выполненные термометрические измерения встречно-штыревых структур на композитных подложках „кремний на алмазе“ демонстрируют существенное снижение температуры поверхности в сравнении с SiC. Это позволяет повысить в 100 раз и более время наработки до отказа за счет понижения температуры канала более чем на $50^{\circ} \mathrm{C}$ при рассеиваемой мощности выше $7 \mathrm{~W}$. Показано, что для структур GaN-on-diamond отсутствуют эффекты саморазогрева при измерении ВАХ до $15 \mathrm{~V}$, что позволяет поднять рассеиваемую мощность на $37 \%$ по сравнению с таковой для коммерческих транзисторов GaN-on-SiC.

Разработанный подход открывает новые возможности для дальнейшего раскрытия потенциала технологии $\mathrm{GaN}$ благодаря уменьшению эффекта саморазогрева за счет эффективного теплоотвода.

\section{Благодарности}

Авторы выражают благодарность В.С. Седову, А.К. Мартьянову, А.С. Алтахову, М.С. Комленоку, В.П. Пашинину, В.И. Конову (Институт общей физики им. А.М. Прохорова РАН) и А.Г. Синогейкину (OОO „Вандер Технолоджис“ ${ }^{\text {) }}$ за изготовление композитных подложек „кремний на алмазе“, а также А.А. Кищинскому (АО „Микроволновые системы“ корпусировании кристаллов.

\section{Финансирование работы}

Работа выполнена при финансовой поддержке Национального исследовательского центра „Курчатовский институт“ (приказ № 2753 от 28.10.2021г.).

\section{Конфликт интересов}

Авторы заявляют, что у них нет конфликта интересов.

\section{Список литературы}

[1] P. Fay, D. Jena, P. Maki, High-frequency GaN electronic devices (Springer, Cham, 2020), p. 1-40.

DOI: $10.1007 / 978-3-030-20208-8$

[2] $M A C O M-R F$ Power Amplifier - GaN [Электронный ресурc]. URL: https://www.macom.com/products/rfpower-amplifiers- 5w/rf-power-amplifier-gan (дата обращения 15.10.2021).

[3] A.V. Inyushkin, A.N. Taldenkov, V.G. Ralchenko, A.P. Bolshakov, A.V. Koliadin, A.N. Katrusha, Phys. Rev. B, 97 (14), 144305 (2018). DOI: 10.1103/PhysRevB.97.144305

[4] S. Hiza, M. Fujikawa, Y. Takiguchi, K. Nishimura, E. Yagyu, T. Matsumae, Y. Kurashima, H. Takagi, M. Yamamuka, in 2019 Int. Conf. on solid state devices and materials (Nagoya University, Japan, 2019), p. 467. DOI: 10.7567/SSDM.2019.K-4-04

[5] Y. Minoura, T. Ohki, N. Okamoto, A. Yamada, K. Makiyama, J. Kotani, S. Ozaki, M. Sato, N. Nakamura, Jpn. J. Appl. Phys., 59 (SG), SGGD03 (2020). DOI: 10.7567/1347-4065/ab5b68

[6] Y. Zhou, R. Ramaneti, J. Anaya, S. Korneychuk, J. Derluyn, H. Sun, J. Pomeroy, J. Verbeeck, K. Haenen, M. Kuball, Appl. Phys. Lett., 111 (4), 041901 (2017). DOI: $10.1063 / 1.4995407$

[7] М.Я. Черных, И.С. Езубченко, И.О. Майборода, И.А. Черных, Е.М. Колобкова, П.А. Перминов, В.С. Седов, А.С. Алтахов, А.А. Андреев, Ю.В. Грищенко, А.К. Мартьянов, В.И. Конов, М.Л. Занавескин, Рос. нанотехнологии, 15 (6), 820 (2020). DOI: 10.1134/S1992722320060072

[8] И.О. Майборода, И.А. Черных, В.С. Седов, А.С. Алтахов, А.А. Андреев, Ю.В. Грищенко, Е.М. Колобкова, А.К. Мартьянов, В.И. Конов, М.Л. Занавескин, Письма в ЖТФ, 47 (7), 13 (2021). DOI: $10.21883 /$ PJTF.2021.07.50792.18630 [I.O. Maiboroda, I.A. Chernykh, V.S. Sedov, A.S. Altakhov, A.A. Andreev, Yu.V. Grishchenko, E.M. Kolobkova, A.K. Mart'yanov, V.I. Konov, M.L. Zanaveskin, Tech. Phys. Lett. (2021). DOI: 10.1134/S1063785021040118].

[9] S. Lee, R. Vetury, J.D. Brown, S.R. Gibb, W.Z. Cai, J. Sun, D.S. Green, J. Shealy, in 2008 IEEE Int. Reliability Physics Symp. (Phoenix, USA, 2008), p. 446. DOI: 10.1109/RELPHY.2008.4558926 